\title{
PERFORMANCE INDEXES: SIMILARITIES AND DIFFERENCES
}

Dsc. André Machado Caldeira

Fuzzy Consultoria Ltda, Brazil

E-mail: amcaldeira@sulamerica.com.br

MSc. Walter Gassenferth

Faculdades IBMEC/RJ, Brazil

E-mail:wgassen@ibmecrj.edu.br; wgassenferth@timbrasil.com.br

MSc. Giovanna Lamastra Pacheco

Faculdades IBMEC/RJ, Brazil

E-mail: gpacheco@ibmecrj.edu.br

Dsc. Maria Augusta Soares Machado

Faculdades IBMEC/RJ, Brazil

E-mail: mmachado@ibmecrj.br

Submission: 09/02/2013

Accept: 21/02/2013

\section{ABSTRACT}

The investor of today is more rigorous on monitoring a financial assets portfolio. He no longer thinks only in terms of the expected return (one dimension), but in terms of risk-return (two dimensions). Thus new perception is more complex, since the risk measurement can vary according to anyone's perception; some use the standard deviation for that, others disagree with this measure by proposing others. In addition to this difficulty, there is the problem of how to consider these two dimensions. The objective of this essay is to study the main performance indexes through an empirical study in order to verify the differences and similarities for some of the selected assets. One performance index proposed in Caldeira (2005) shall be included in this analysis.

Keywords: Return, Risk, Performance Index 
INDEPENDENT JOURNAL OF MANAGEMENT \& PRODUCTION (IJM\&P)

http://www.ijmp.jor.br

v. 4, n. 1, January - June 2013.

ISSN: 2236-269X

DOI: 10.14807/ijmp.v4i1.53

\section{INTRODUCTION}

The existence of risk means that the investor cannot associate a simple figure, or return, with an investment in any asset. Analysis must be made through a series of returns and associated with its probability of occurrence, called frequency distribution or distribution of returns.

In an investment analysis the two most used attributes of a distribution are a measure of central tendency, called expected return, and a risk measure; the standard deviation is the most used. Investors should not and do not have a simple asset as an investment, they have groups or portfolios of assets. One important aspect in risk analysis is that the risk of a portfolio is more complex than a simple mean of the risk of individual assets; it is influenced by the level of dependence among the assets.

This need to think in terms of risk-return, that is, a bi-dimensional analysis, brings about a certain difficulty. In order to make analysis easy, performance indexes were created, which generally are ratios between a measure of return and a measure of risk. The risk measures, in turn, can be very different according to the perception of "what is risk?"

The most used performance measure is the Sharpe Index (SHARPE, 1966), which uses the standard deviation as a measure of risk. Another index that appeared in that same time was proposed by Treynor (1965), who uses the Beta of the CAPM (SHARPE,1964) model as a measure of risk.

Jensen (1968) suggests a change to the CAPM model by not fixing the intercept as zero. This intercept becomes known as Jensen's Alfa and is used as a performance index.

As from the separation of the concept of risk from that of uncertainty, Sortino (SORTINO \& VAN DER MEER, 1991) defines risk as the possibility of occurrence of an event, that is, he separates the bad uncertainty and proposes the use of the negative variance (FISHBURN, 1977) as a measure of risk.

Entropy is used as a measure of risk by Philippatos (PHILIPPATOS \& WILSON, 1972), and by using this concept, a performance index is proposed by Caldeira (2005). 
INDEPENDENT JOURNAL OF MANAGEMENT \& PRODUCTION (IJM\&P)

http://www.ijmp.jor.br

v. 4, n. 1, January - June 2013.

ISSN: 2236-269X

DOI: 10.14807/ijmp.v4i1.53

The objective of this paper is to introduce the main performance indexes and detail their ideas and formulations. Since no performance index is absolute because it depends mainly on the definition of risk it uses, performance indexes of financial assets analysis will be compared in order to observe their similarities and differences.

\section{MAIN PERFORMANCE INDEXES}

\subsection{The Sharpe Index}

This Sharpe (1966) Index stems from the theory of portfolio analysis through the ratio between return and risk, as measured by the mean and standard deviation respectively. This performance index was made formal through the work of William Sharpe (1966).

Empirical studies show that the market responds very quickly to new information by affecting the value of the stocks; by this, the market tends to be perfectly informed and each player uses the information in the same way.

The performance forecast of a portfolio is described by two measures: the expected Rate of Return (RP) and the forecast of variability, or risk, expressed by the standard deviation of the return $(\sigma P)$. A hypothesis is that all investors are able to invest funds in a risk-free common asset and borrow funds at the same rate. At some point, all investors share the same forecasts regarding the future performance of the assets (hence, of the portfolios). On these conditions, all efficient portfolios will converge to a linear function given by:

$R_{P}=R_{F}+b \sigma_{P}$

Where $\mathrm{RF}$ is the return of the risk-free asset and $\mathrm{b}$ is the risk premium.

If we highlight $b$, we have:

$b=\frac{R_{P}-R_{F}}{\sigma_{P}}=I_{\text {Sharpe }}$

This relation became known as the Sharpe Index (ISharpe)

The best portfolio will be the one with the highest ISharpe. If more than one portfolio is efficient, all of them must be on the same straight line, that is, have equal indexes. 
INDEPENDENT JOURNAL OF MANAGEMENT \& PRODUCTION (IJM\&P)

http://www.ijmp.jor.br

V. 4, n. 1, January - June 2013.

ISSN: 2236-269X

DOI: 10.14807/ijmp.v4i1.53

This index deals with future performance forecasts. At some points, the best projection of return is the mean of the historical returns. The same happens with the forecast for the standard deviation, for which we use the historical standard deviation. Therefore, it is usually used as:

$I_{\text {Sharpe }}=\frac{\bar{R}_{P}-R_{F}}{\hat{\sigma}_{P}}$

In the event of a negative Sharpe Index, it is not applicable, since it represents a risk premium, and investors are contrary to risk, the premium must be positive; that is why it loses interpretability.

Considering that the Sharpe Index represents a risk premium, the following restriction exists:

$I_{\text {Sharpe }}>0$, since a negative premium means loss.

\subsection{The Treynor Index}

Treynor (1965) proposes to separate risk according to its nature. A part of the risk is produced by the general floating of the market (volatility of the stock market), and the other part results from the floatation of a certain asset of the fund. The consequences of practical importance for each one of these mentioned risks are:

I. The effect of management of the rate of return of an investment made in a period of time is normally amortized by the floatation of the market. Market oscillations imply in better (or worse) profitability for the case of more unsteady funds that will have better (or worse) profitability than those les unsteady funds. For any example with a reasonable-sized interval, the mean of return is still dominated by market trend.

II. Measures of medium return do not provide support for those investors that are contrary to risk. There is some importance in the floatation in certain stocks, for portfolios with few stocks. In order to avoid this risk, the investors diversify their portfolios. The importance tied to the risk varies from investor to investor; for that reason, no absolute measure of fund performance is viable.

The first step to obtain a satisfactory measure of performance is to relate the expected return of the portfolio (RP) with the return of a mean market index (RM), 
INDEPENDENT JOURNAL OF MANAGEMENT \& PRODUCTION (IJM\&P)

http://www.ijmp.jor.br

v. 4, n. 1, January - June 2013.

ISSN: 2236-269X

DOI: 10.14807/ijmp.v4i1.53

that is, take out the influence of the market from the asset return. This relation is called characteristic line and is defined by the following linear function:

$R_{P}=\alpha+\beta R_{M}$

The parameters of the characteristic line can be estimated through statistical methods (such as that of Square Minimums). Interesting is that this trend is stationary with time, not considering the floatation of the short-term return.

It contains information both on the rate of return and risk; its inclination measures volatility. A steep inclination means that the rate of return of the fund involved is market floatation-sensitive; a smooth inclination indicates that the fund involved is relatively market floatation-insensitive.

This line might not be very clear or significant (for instance, low R2). It means that not all of the risk of the fund involved is explained through market floatation.

The performance of a fund can be measured by the tangent of the angle of inclination. The demonstration of the formula stems directly from geometry $\tan (\gamma)=\frac{\bar{R}_{P}-R_{F}}{\beta}$

where $\gamma$ is the angle of inclination of the characteristic line, and $\beta$ is the symbol of volatility (measured by the inclination of the characteristic line).

\subsection{Jensen's Alpha}

Jensen's Alpha stems directly from the application of the theoretical results of CAPM, independently derived by Sharpe (1964), Lintner (1965) and Treynor. (1965) Consider that the return of portfolio $P$ can be written as:

$\widetilde{R}_{P}-R_{F}=\beta_{P}\left[\widetilde{R}_{M}-R_{F}\right]+\widetilde{e}_{P}$

Where:

$\widetilde{R}_{P}=$ Rate of return of portfolio $P$,

$R_{F}=$ Risk-free rate

$\beta_{P}=$ Measurement of risk 
INDEPENDENT JOURNAL OF MANAGEMENT \& PRODUCTION (IJM\&P)

http://www.ijmp.jor.br

V. 4, n. 1, January - June 2013.

ISSN: 2236-269X

DOI: 10.14807/ijmp.v4i1.53

$\widetilde{R}_{M}=$ Expected rate of return from the market

$\widetilde{e}_{P}=$ Normal error id

Should one wish to estimate the systemic risk of a non-managed asset or portfolio, estimate through regression is an efficient one. Nevertheless, care must be taken when applying this equation to managed portfolios. If a manager has better forecasts (due to privileged information, for instance), he will systematically tend to select portfolios that provide $\widetilde{e}_{P}>0$. Therefore, his portfolio will earn more than the "ordinary" risk premium for its level of risk. We should be aware of such possibility on estimating the systemic risk of a managed portfolio.

The relaxation of the equation for such possibility can be done simply by breaking off the need of regression to go through origin. Therefore, existence of a constant in equation (1) by using (2) as an estimated equation is allowed.

$\widetilde{R}_{P}-R_{F}=\alpha_{P}+\beta_{P}\left[\widetilde{R}_{M}-R_{F}\right]+\widetilde{u}_{P}$

The new error term $\widetilde{u}_{P}$ will now have $E\left(\widetilde{u}_{P}\right)=0$.

So, if the portfolio manager is able to foresee the prices of the assets, the intercept, $\alpha_{P}$, in equation (7), will be positive. Definitely, this represents an average rate of increment in the portfolio for a time that is solely due to the ability to foresee the future price of the assets. It is interesting to notice that an ingenuous random selection of assets is expected to have an intercept that equals zero. Therefore, if a manager does not make good choices, Alpha tends to be negative.

\subsection{The Sortino Index}

A number of scholars and analysts complain that the standard deviation and beta are not relevant measures in many investment situations because they do not distinguish good risk from bad risk.

Sortino (1991) maintains that the knowledge developed to make investment decisions under conditions of uncertainty, and for which Harry Markowitz, William Sharpe, and Merton Miller received the Nobel Prize, requires a clear distinction between risk and uncertainty. 
INDEPENDENT JOURNAL OF MANAGEMENT \& PRODUCTION (IJM\&P)

http://www.ijmp.jor.br

v. 4, n. 1, January - June 2013.

ISSN: 2236-269X

DOI: 10.14807/ijmp.v4i1.53

Risk and return are inseparable components of the concept of uncertainty. Uncertainty in the financial market is described in terms of the variance of the possible returns and their chance of occurrence. The distribution of probability describes the form of uncertainty.

In many investment decisions there is a minimum expected return to achieve a target like, for example, the portfolio of an insurance company needs a minimum return to meet its obligations with its insurants. We can describe it like the minimum return that must be achieved in order to avoid bad consequences. Those returns higher than the minimum acceptable return (MAR) ensure meeting the target; therefore, there is no risk. The more the return surpasses the MAR, the lower the risk of a bad result.

We can say that the standard deviation captures the risk associated to reach the mean, but it can be completely dissociated from bad results, for only those returns below the MAR incur in risk, and the lower below the MAR, the greater is the risk.

Therefore, an asset $A$ that has a minimum return above the MAR has no risk. If compared to an asset $B$ that has a lower standard deviation and a minimum return value below the MAR, this asset $B$ has a higher risk.

Hence, in situations where there is an identifiable MAR, which is economically significant, we must tell the good volatility from the bad one.

Measuring the bad volatility can be done through negative variance (FISHBURN, 1977); therefore, risk is shown as:

$S D_{P}=\frac{1}{n} \sum_{i=1}^{n}\left(\max \left(R M A-R_{P i}, 0\right)\right)^{2}$

Consequently, the risk-return index proposed by Sortino is given by:

$I_{\text {Sortino }}=\frac{\bar{R}_{p}-R_{F}}{S D_{P}}$

\subsection{The Caldeira Index}

This index was proposed due to the comparison of uncertainty through variance not be valid for distributions of different families. As for the indexes 
INDEPENDENT JOURNAL OF MANAGEMENT \& PRODUCTION (IJM\&P)

http://www.ijmp.jor.br

V. 4, n. 1, January - June 2013.

ISSN: 2236-269X

DOI: 10.14807/ijmp.v4i1.53

proposed by Sharpe (1966) and Treynor (1965), there is a hypothesis that the data are Gaussian.

By observing the limitation in the use of variance as a measure of risk, Philippatos and Wilson (1972) propose replacement of variance by entropy. This measure of risk, in turn, is more general and allows for the utilization of assets with any distribution.

Still on this line, Philippatos and Gressis (1975) conduct a comparative study between the mean-variance model and the mean-entropy model, where he observes that the models are equivalent for normal and uniform distributions. Concerning the log-normal distribution, the results are not equivalent, since entropy becomes a function not only of variance, but also of mean. This result was achieved due to the asymmetry of this distribution. Nevertheless, this model, despite being innovative, did not move forward due to the difficulty in implementing the theory.

The basic principle of the index proposed by Caldeira (2005) is to allow for the comparison of data generated by any distribution without the need of the initial knowledge of its generating function, thus turning this model into a generalization of the Sharpe model. The generating function is estimated through the Parzen Windows (PARZEN, 1962). Therefore, this index can be written as:

$$
I_{\text {Caldeira }}=\frac{\bar{R}_{p}-\bar{R}_{F}}{\sqrt{\frac{\mathrm{e}^{2 \mathrm{~h}(\mathrm{P})-1}}{2 \pi}}}
$$

Where $h(P)$ is the differential entropy of the portfólio.

\section{EMPIRICAL STUDY}

This essay proposes to compare the performance indexes presented in the previous chapter to financial assets (it can be used with portfolios as well). Ten financial assets traded at BOVESPA were selected and their properties studied. The data concerning the daily returns of these assets were collected from the page of "Easy Invest" brokers (www.easyinvest.com.br). The time span of the data ranges from August 10th 2000 to September 27th 2004.

The descriptive statistics (see Table 1) show the big differences among these assets. Assets ARCZ3, CRUZ3 and VALE5 had average daily profitability above 


\section{INDEPENDENT JOURNAL OF MANAGEMENT \& PRODUCTION (IJM\&P)}

http://www.ijmp.jor.br

V. 4, n. 1, January - June 2013.

ISSN: 2236-269X

DOI: 10.14807/ijmp.v4i1.53

$0.15 \%$, whereas assets BRAP4 and TNLP4, they had averages lower than $0.07 \%$. With relation to the first measure of risk, the standard deviation, asset ELET6 is the one with the highest risk followed by BRAP4 and EMBR4; and those assets with the lowest risk are VALE5, ARCZ3 and PETR4, respectively.

As for the second measure of risk, the semi standard deviation (square root of the semi variance), asset ELET6 is the most risky, followed closely by EMBR4, while asset ARCZ3 has the lowest level of risk, followed by VALE5. As for the risk measured by the semi standard deviation, asset ARCZ3 is less risky than VALE5, which differs from the perception of risk measured by the standard deviation. This difference is explained by the high asymmetry coefficient of asset ARCZ3, which, under the optics of loss, becomes more attracting. This same difference can be perceived when comparing assets AMBV4 and CRUZ3.

Asset ITAU4 is the one with the highest risk under the optics of entropy followed by ELET6 and TNLP4. Asset ARCZ3, again, is the one with the lowest risk; the distribution function estimated through the Parzen Windows for this asset, see Figure 3, shows a great concentration of return around the mean, and for that reason its kurtosis is very high.

Table 1: Descriptive statistics of returns

\begin{tabular}{lcccccc}
\hline Ativo & Média & DP & Semi - DP & Coef. de Assimetria & Exc Curtose & Entropia \\
\hline ITAU4 & 0,095 & 2,347 & 1,570 & 0,147 & 0,753 & 3,887 \\
BRAP4 & 0,064 & 2,929 & 1,974 & 0,128 & 2,202 & 3,495 \\
ARCZ3 & 0,152 & 2,089 & 1,254 & 1,228 & 11,165 & 2,503 \\
AMBV4 & 0,087 & 2,216 & 1,542 & $-0,275$ & 4,298 & 3,496 \\
CRUZ3 & 0,222 & 2,346 & 1,496 & 0,547 & 6,121 & 3,430 \\
VALE5 & 0,163 & 2,009 & 1,282 & 0,347 & 1,923 & 3,691 \\
EMBR4 & 0,146 & 2,929 & 2,018 & $-0,235$ & 4,014 & 3,496 \\
ELET6 & 0,097 & 3,234 & 2,165 & 0,213 & 0,673 & 3,879 \\
TNLP4 & 0,042 & 2,564 & 1,764 & 0,149 & 1,299 & 3,792 \\
PETR4 & 0,117 & 2,159 & 1,457 & 0,068 & 1,877 & 3,748 \\
\hline
\end{tabular}

Stocks PETR4, TNLP4 and ELET6 (Figures 1, 2 and 3, respectively) are slightly asymmetrical and their tails are a little heavier than the normal curve. Stocks EMBR4 and VALE5 (Figures 4 and 5, respectively) are also asymmetrical with the negative values of the latter being well concentrated until $-4 \%$. Assets CRUZ3, AMBV4 and ITAU4 (Figures 6, 7 and 10, respectively) show a greater concentration in the middle and a slight asymmetry with a greater excess kurtosis. 
INDEPENDENT JOURNAL OF MANAGEMENT \& PRODUCTION (IJM\&P)

http://www.ijmp.jor.br

v. 4, n. 1, January - June 2013.

ISSN: 2236-269X

DOI: 10.14807/ijmp.v4i1.53

Stocks ARCZ3 and BRAP4 (Figures 8 and 9, respectively) have very different characteristics from the rest. The former has its values very concentrated around its mean, displacing itself a lot from the Normal curve. As for BRAP4, it is concentrated toward the center, much lighter than ARCZ3, but it is a tri-modal distribution and its asymmetry is perceived mainly due to a 'gap' between 2.5 and 5 , which does not exist in the negative part of the distribution.

It is possible to see that all of the curves are a little out of normal; because of that, the Jarque-Bera (Table 2) test rejected this hypothesis. In addition to this rejection, the difference in asset distributions is clear, each distribution with a more remarkable feature. Therefore, the estimates given by Parzen Windows maintain important characteristics of distribution such as asymmetry and high kurtosis.

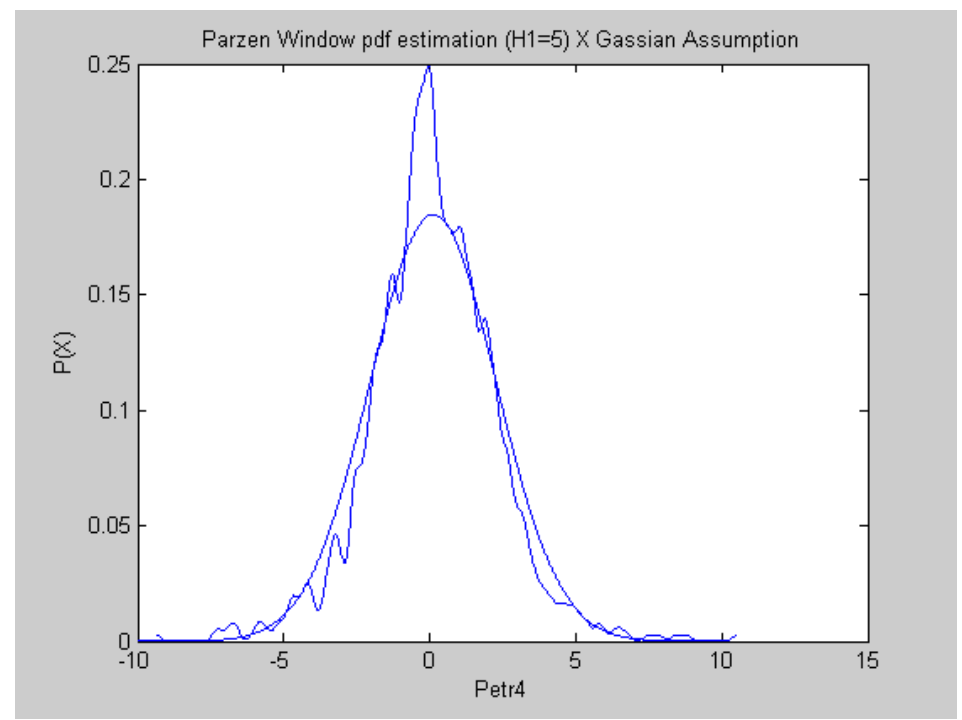

Figure 1: Estimate of the fsd of asset Petr4 via Parzen Windows $(\mathrm{H} 1=5)$.

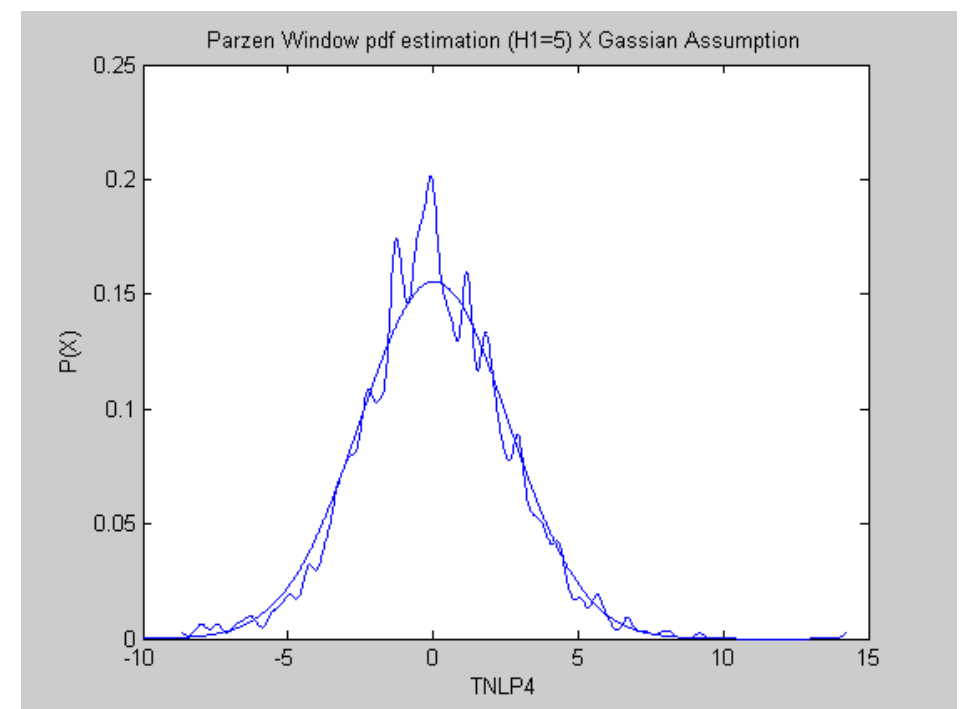

Figure 2: Estimate of the fsd of asset TNLP4 via Parzen Windows $(\mathrm{H} 1=5)$. 
INDEPENDENT JOURNAL OF MANAGEMENT \& PRODUCTION (IJM\&P)

http://www.ijmp.jor.br

v. 4, n. 1, January - June 2013.

ISSN: 2236-269X

DOI: 10.14807/ijmp.v4i1.53

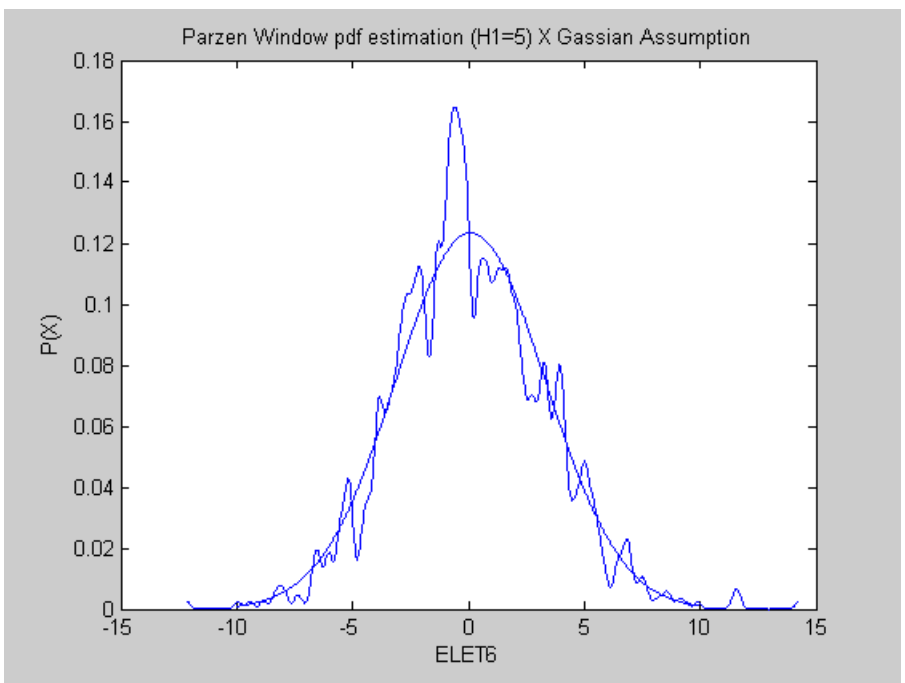

Figure 3: Estimate of the fsd of asset ELET6 via Parzen Windows $(\mathrm{H} 1=5)$.

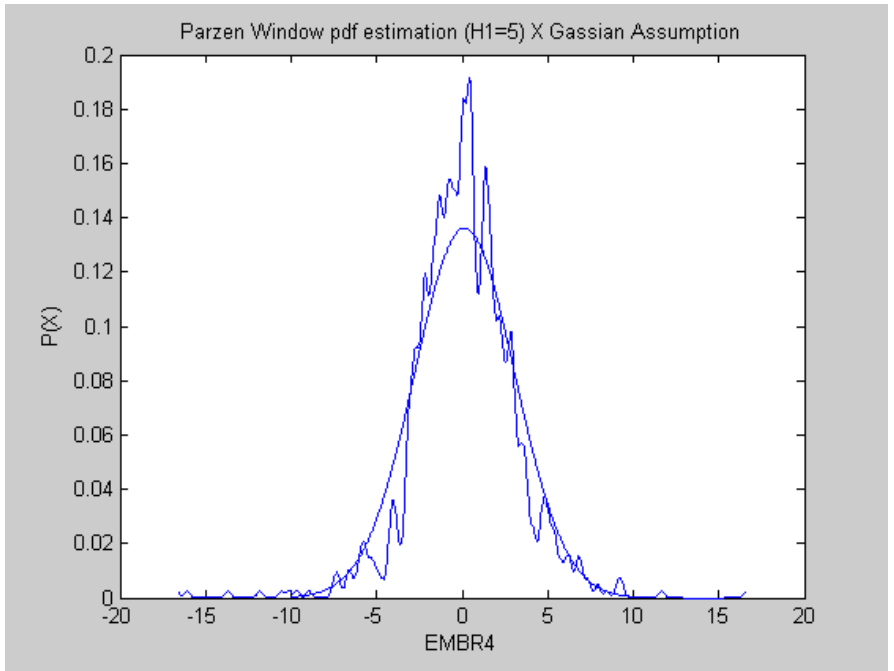

Figure 4: Estimate of the fsd of asset EMBR4 via Parzen Windows $(\mathrm{H} 1=5)$.

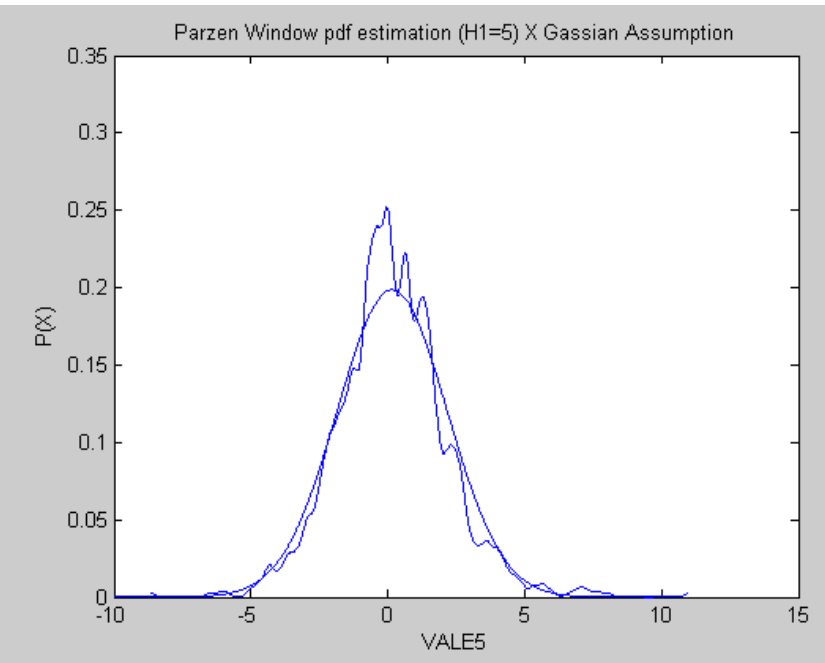

Figure 5: Estimate of the fsd of asset VALE5 via Parzen Windows $(\mathrm{H} 1=5)$. 
INDEPENDENT JOURNAL OF MANAGEMENT \& PRODUCTION (IJM\&P)

http://www.ijmp.jor.br

v. 4, n. 1, January - June 2013.

ISSN: 2236-269X

DOI: 10.14807/ijmp.v4i1.53

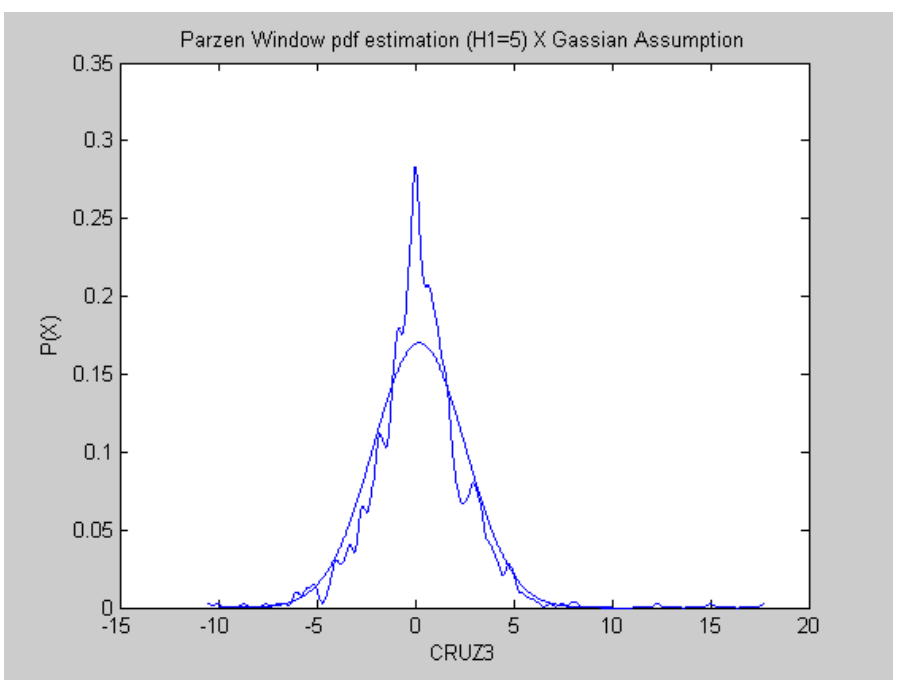

Figure 6: Estimate of the fsd of asset CRUZ3 via Parzen Windows $(\mathrm{H} 1=5)$.

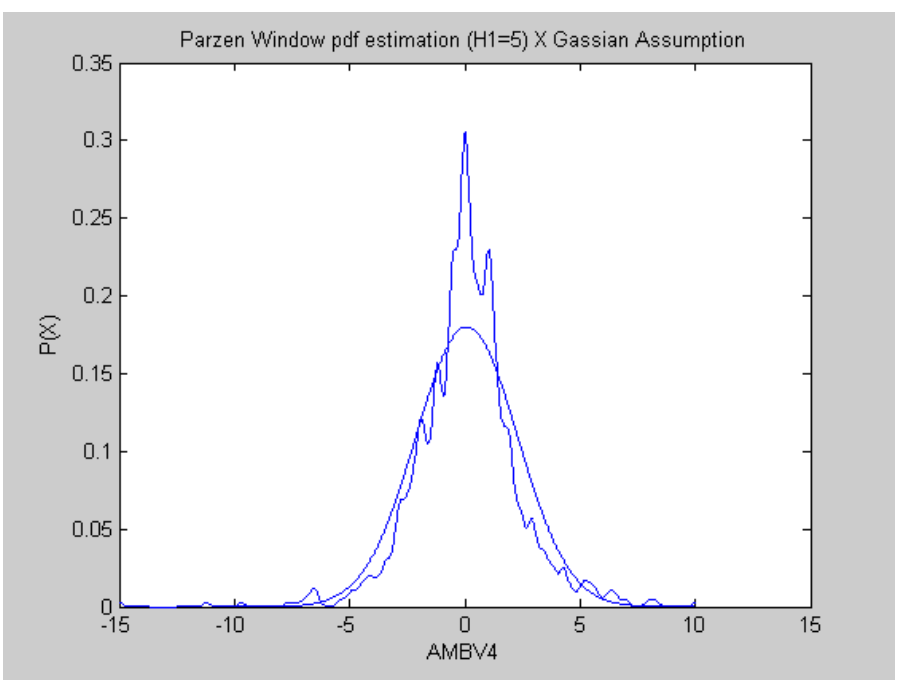

Figure 7: Estimate of the fsd of asset AMBV4 via Parzen Windows $(\mathrm{H} 1=5)$.

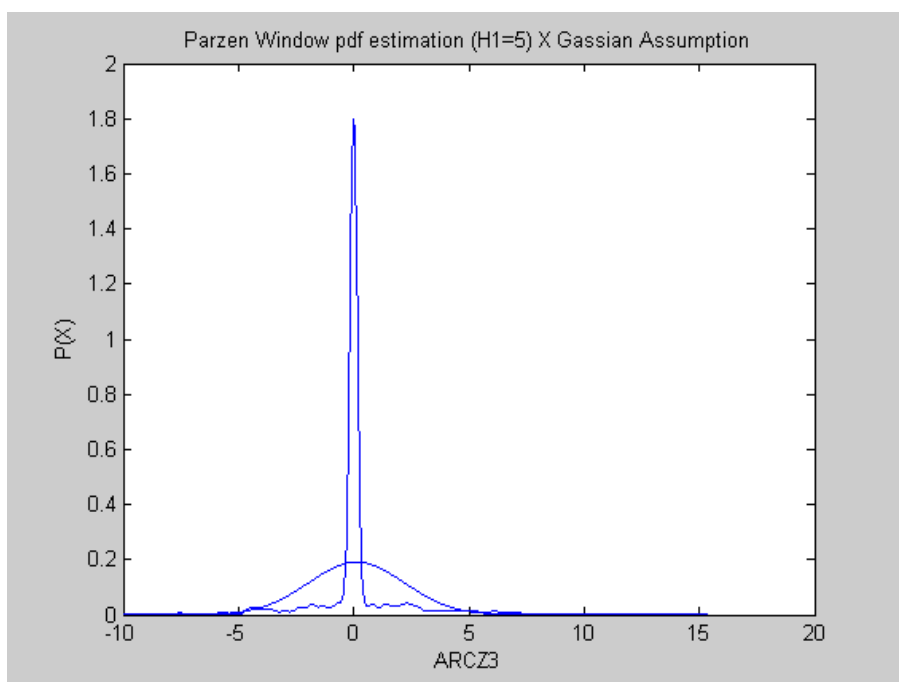

Figure 8: Estimate of the fsd of asset ARCZ3 via Parzen Windows $(\mathrm{H} 1=5)$. 
INDEPENDENT JOURNAL OF MANAGEMENT \& PRODUCTION (IJM\&P)

http://www.ijmp.jor.br

v. 4, n. 1, January - June 2013.

ISSN: 2236-269X

DOI: 10.14807/ijmp.v4i1.53

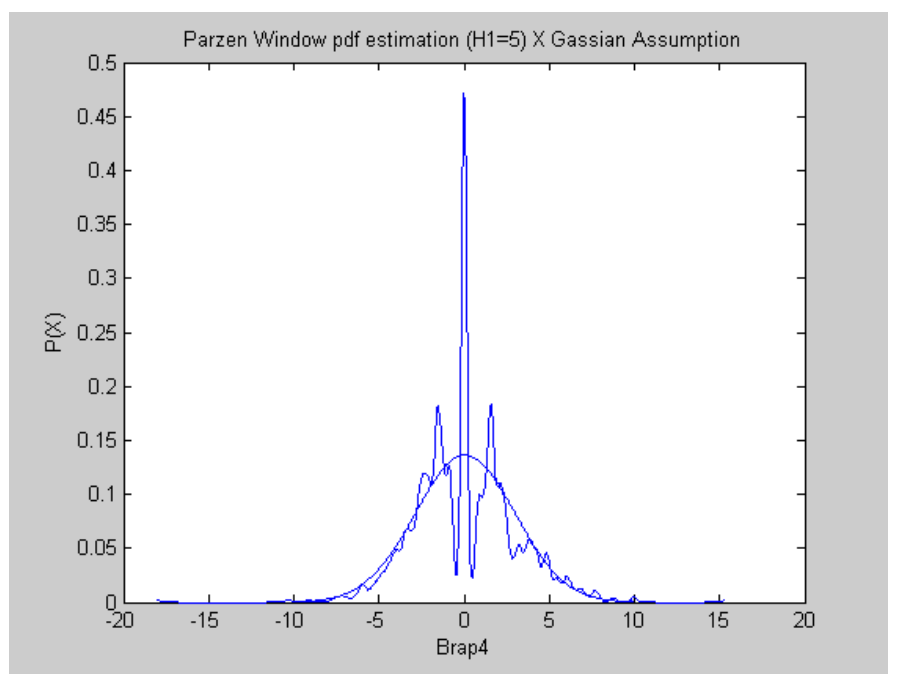

Figure 9: Estimate of the fsd of asset BRAP4 via Parzen Windows $(\mathrm{H} 1=5)$.

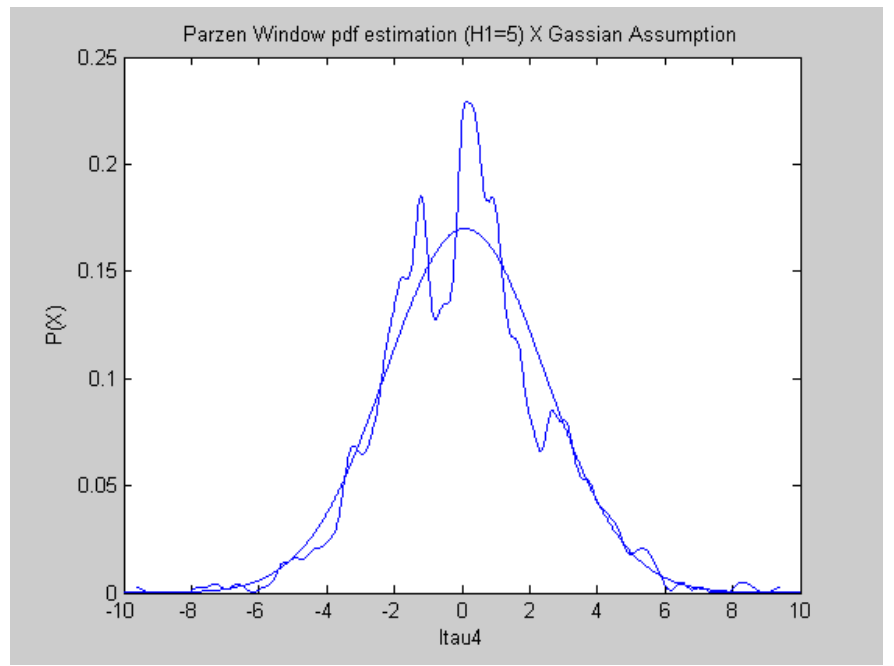

Figure 10: Estimate of the fsd of asset ITAU4 via Parzen Windows $(\mathrm{H} 1=5)$.

\begin{tabular}{lr} 
Table 2 : Jarque-Bera Normality Test \\
\hline Ação & JB -test (p-value) $\left(\mathbf{X} \mathbf{1 0}^{\wedge} \mathbf{- 5}\right)$ \\
\hline ITAU4 & 0,1942 \\
BRAP4 & 0 \\
ARCZ3 & 0 \\
AMBV4 & 0 \\
CRUZ3 & 0 \\
VALE5 & 0 \\
EMBR4 & 0 \\
ELET6 & 0 \\
TNLP4 & 0,2795 \\
PETR4 & 0 \\
\hline
\end{tabular}

Table 3 shows that, with relation to the Beta risk, asset ELET6 is the riskiest, followed by TNLP4. Under this risk viewpoint, the least risky is asset ARCZ3. The problem with this measure of risk is that not all assets have a great adherence (adjusted R2) to a market index (IBOVESPA). Therefore, the estimate for the Beta may not represent the risk involved well. 
INDEPENDENT JOURNAL OF MANAGEMENT \& PRODUCTION (IJM\&P)

http://www.ijmp.jor.br

v. 4, n. 1, January - June 2013.

ISSN: 2236-269X

DOI: 10.14807/ijmp.v4i1.53

Table 3: Beta in relation to the IBOVESPA

\begin{tabular}{lcc}
\hline Ativo & Beta & R2 - ajust. \\
\hline ITAU4 & 0,787 & $41,90 \%$ \\
BRAP4 & 0,909 & $35,91 \%$ \\
ARCZ3 & 0,162 & $2,13 \%$ \\
AMBV4 & 0,532 & $21,41 \%$ \\
CRUZ3 & 0,503 & $16,96 \%$ \\
VALE5 & 0,375 & $12,84 \%$ \\
EMBR4 & 0,507 & $56,20 \%$ \\
ELET6 & 1,256 & $56,18 \%$ \\
TNLP4 & 1,171 & $77,85 \%$ \\
PETR4 & 0,741 & $43,84 \%$ \\
\hline
\end{tabular}

From the measures of risk and return, the performance indexes were calculated (Erro! Fonte de referência não encontrada.4). Due to the differences in terms of risk measurement, the absolute results become somehow incomparable. In order to compare the behavior of these indexes, it is necessary to use common references and thus create comparable metrics.

One such way to compare these performance indexes is the classification of investments through each index (Table 4) and so compare the results.

Table 4: Performance Indexes

\begin{tabular}{lccccc}
\hline Ativo & Índice Sharpe & Índice Traynor & Alfa Jensen & Índice Sortino & Índice Caldeira \\
\hline ITAU4 & 0,040 & 0,121 & 0,054 & 0,060 & 0,008 \\
BRAP4 & 0,022 & 0,070 & 0,016 & 0,032 & 0,008 \\
ARCZ3 & 0,073 & 0,937 & $0,144^{*}$ & 0,121 & 0,051 \\
AMBV4 & 0,039 & 0,163 & 0,059 & 0,056 & 0,011 \\
CRUZ3 & 0,095 & 0,442 & $0,144^{*}$ & 0,149 & 0,030 \\
VALE5 & 0,081 & 0,435 & $0,144^{*}$ & 0,127 & 0,017 \\
EMBR4 & 0,050 & 0,288 & 0,120 & 0,072 & 0,018 \\
ELET6 & 0,030 & 0,077 & 0,031 & 0,045 & 0,008 \\
TNLP4 & 0,016 & 0,036 & $-0,020$ & 0,024 & 0,004 \\
PETR4 & 0,054 & 0,158 & 0,078 & 0,080 & 0,011 \\
\hline
\end{tabular}

One such way to compare these performance indexes is the classification of investments through each index (Erro! Fonte de referência não encontrada.) and so compare the results.

Table 5: Classification of assets according to the performance indexes

\begin{tabular}{lccccc}
\hline Ativo & Indice Sharpe & Indice Traynor & Alfa Jensen & Indice Sortino & Índice Caldeira \\
\hline ITAU4 & 6 & 7 & 7 & 5 & 8 \\
BRAP4 & 9 & 9 & 9 & 9 & 9 \\
ARCZ3 & 3 & 1 & 3 & 3 & 1 \\
AMBV4 & 7 & 5 & 6 & 6 & 6 \\
CRUZ3 & 1 & 2 & 2 & 1 & 2 \\
VALE5 & 2 & 3 & 1 & 2 & 4 \\
EMBR4 & 5 & 4 & 4 & 7 & 3 \\
ELET6 & 8 & 8 & 8 & 8 & 7 \\
TNLP4 & 10 & 10 & 10 & 10 & 5 \\
PETR4 & 4 & 6 & 5 & 4 & 5 \\
\hline
\end{tabular}




\section{INDEPENDENT JOURNAL OF MANAGEMENT \& PRODUCTION (IJM\&P)}

http://www.ijmp.jor.br

V. 4, n. 1, January - June 2013.

ISSN: 2236-269X

DOI: 10.14807/ijmp.v4i1.53

As to the classification of that asset with the poorest performance result, all the indexes selected asset TNLP4, and likewise for the second poorest result, asset BRAP4. The eighth place (except classification by the Caldeira Index) is for asset ELET6. As for the other positions, the concordance differences are greater.

Asset AMBV4 is in seventh place according to the Sharpe Index; however; some distribution characteristics of its returns make this asset to go up at least one position regarding the other indexes. By analyzing this asset from the risk and loss viewpoint (Sortino Index), or referring to entropy as a measure of risk, it gains one position to the sixth place.

Regarding asset ITAU4, while the Sortino Index ranks this asset in fifth place, the Sharpe Index ranks it sixth, the Traynor and the Jensen Indexes rank it seventh, and the Caldeira Index rank it eighth. All this difference is due to differences in risk measuring; the returns of this asset have positive asymmetry (Table 1), which reduces the semi standard deviation (measure of risk of the Sortino Index). Regarding the Caldeira Index, the entropy of this distribution is the highest of all, making it the riskiest. This measure of risk makes this investment less attractive from this point of view.

Asset EMBR4 (ranked as the fifth best asset by the Sharpe Index) loses two positions when the Sortino Index is used; this is due to the asymmetry of this distribution. But if the Caldeira Index is used, this is the third best asset, since its entropy has a positive influence.

Both the Sharpe and the Sortino Indexes rank asset Petr4 the fourth best asset. This similarity can be explained through the low coefficient of asymmetry. As to the classification by the Caldeira Index, this asset is prejudiced by entropy, thus ranking fifth place.

Asset ARCZ3 is ranked the third best asset by the Sharpe Index and occupies the same position by the Sortino Index, despite its high asymmetry. Nevertheless, the Caldeira Index considers this asset the best investment due to its low risk (entropy), mainly.

According to the Sharpe metrics, the best and the second best assets are respectively CRUZ3 and VALE5, a result that repeats for the index. For the Caldeira metrics, these assets are classified as second and third respectively. This difference 
INDEPENDENT JOURNAL OF MANAGEMENT \& PRODUCTION (IJM\&P)

http://www.ijmp.jor.br

v. 4, n. 1, January - June 2013.

ISSN: 2236-269X

DOI: 10.14807/ijmp.v4i1.53

occurs mainly due to the low entropy of asset ARCZ3, which makes it the best asset according to this index.

The results for the Traynor Index are not significant, since the CAPM model does not show great adherence for most of the assets. The Jensen's Alpha is significant only in assets VALE5, CRUZ3 and ARCZ3. And this is the respective classification order.

Table 6 shows the result of the correlations among the indexes. Generally speaking, these correlations are high, at a maximum of $99.69 \%$ and minimum of $70.52 \%$.

These results show an almost perfect correlation (99.69\%) between the Sharpe and Sortino Indexes. This result is due to the fact that these assets are only slightly asymmetrical. Regarding the Sharpe Index and the Jensen's Alpha, this result also shows a high correlation (93.77\%). As for the correlation between the Traynor and Caldeira Indexes, it falls to $73.83 \%$ and $70.52 \%$, respectively. This deviation in relation with the Caldeira Index can be explained by the fact that the data do not have a Gaussian distribution.

The Traynor Index has a high correlation with the Caldeira Index (97.8\%), which is reduced when it is compared to the Jansen's Alpha and the Sortino metrics (80.00\% and $77.83 \%$, respectively). The correlation between the Jensen's Alpha and the Sortino Index is pretty high (93.28\%), and with relation with the Caldeira metrics, this correlation is even lower (75.75\%). And the correlation between the Sortino and Caldeira Indexes is $74.50 \%$.

By and large, the Caldeira Index is the one that has the most differences regarding the other ones. This is so because it does not have to work with Gaussian data, which is a hypothesis for the other indexes.

Table 6: Correlation among the indexes

\begin{tabular}{lccccc}
\hline & Indice Sharpe & Indice Traynor & Alfa Jensen & Indice Sortino & Índice Caldeira \\
\hline Indice Sharpe & $100,00 \%$ & $73,83 \%$ & $93,77 \%$ & $99,69 \%$ & $70,52 \%$ \\
Indice Traynor & $73,83 \%$ & $100,00 \%$ & $80,00 \%$ & $77,83 \%$ & $97,38 \%$ \\
Alfa Jensen & $93,77 \%$ & $80,00 \%$ & $100,00 \%$ & $93,28 \%$ & $75,75 \%$ \\
Indice Sortino & $99,69 \%$ & $77,83 \%$ & $93,28 \%$ & $100,00 \%$ & $74,50 \%$ \\
Índice Caldeira & $70,52 \%$ & $97,38 \%$ & $75,75 \%$ & $74,50 \%$ & $100,00 \%$ \\
\hline
\end{tabular}


INDEPENDENT JOURNAL OF MANAGEMENT \& PRODUCTION (IJM\&P)

http://www.ijmp.jor.br

v. 4, n. 1, January - June 2013.

ISSN: 2236-269X

DOI: 10.14807/ijmp.v4i1.53

\section{CONCLUSIONS}

This paper shows that there are different metrics to assess investments. The ones shown herein differ regarding the understanding of risk. Risk is a subjective concept that we try to decode by adopting objective metrics. However, the understanding as to what risk metrics é the best adopted one shall depend mainly on who is involved in the matter.

The standard deviation used as a measure of risk by the Sharpe Index represents well the dispersion around the mean; however, Sortino presents a feature that was not predicted by Sharpe, asymmetry. This asymmetry creates the necessity to separate risks; as a risk of loss, the semi standard deviation is adopted by the index proposed by Sortino.

The index developed by Caldeira aims to measure all the uncertainty involved in estimating the mean, thus bringing entropy as a measure of risk and allowing for the comparison of any distribution. This index has a similar problem to that of the Sharpe Index: it does not separate good uncertainty from bad uncertainty (the problem that originated the Sortino Index). This can be an alteration to be used in this index.

The indexes using the CAPM to be estimated have a major problem. If the model is not well adjusted, this metrics will be not. In this essay only three Jensen's Alphas were significant, whereas only one model had R2 above $70 \%$ and only three above $50 \%$.

By and large, the indexes had pretty close results in terms of investment classification, and this can be seen in the matrix of correlation of the indexes, which has the lowest correlation around $70 \%$. This means that, apparently, all of the risk metrics used tend to be an approximation to the subjective term risk.

The Sortino Index can be a more robust index if the objective is measuring of the index of loss; however, despite the Caldeira Index does not separate risk of loss from risk of gain, its measure of risk allows for the comparison of any distribution.

Joining the ideas from both the Sortino and the Caldeira Indexes can bring about an even more robust index that allows for measuring entropy for those values below an established minimum (risk of loss). 
INDEPENDENT JOURNAL OF MANAGEMENT \& PRODUCTION (IJM\&P)

http://www.ijmp.jor.br

V. 4, n. 1, January - June 2013.

ISSN: 2236-269X

DOI: 10.14807/ijmp.v4i1.53

\section{REFERENCES}

CALDEIRA, A. M. (2005). Seleção de Carteiras Utilizando Técnicas Não

Paramétricas. Tese de Mestrado, Pontifícia Universidade Católica do Rio de Janeiro.

FISHBURN, P. (1980). Foundations of risk measurement: I. Risk as a probability of loss. Management Science, n. 30, p. 396-406.

JENSEN, M.C. (1968). The Performance of Mutual Funds in the Period 1945-1964. The Journal of Finance, p. 389-416.

LINTNER, J. (1965). Security Prices, Risk, and Maximal Gains from Diversification. Journal of Finance, n. 20, p. 394-419.

PARZEN, E. (1962). On Estimation of a Probability Density Function and Mode. Annals of Math. Statistics, n. 33, p. 1065-1076.

PHILIPPATOS, G. \& C. WILSON (1972). Entropy, Market Risk, and the Selection of Efficient Portfolios. Applied Economics, n. 4, p. 209-220.

PHILIPPATOS, G. \& N. GRESSIS (1975). Conditions of Equivalence Among EV, SSD and EH Portfolio Selection Criteria: The Case for Uniform Normal and Lognormal Distributions. Management Science, p. 617-625.

SHARPE, W. (1966). Mutual :Fund Performance. Journal of Business, p. 119-138.

SHARPE, W. (1964). Capital asset prices: A theory of capital market equilibrium under conditions of risk. Journal of Finance, n. 19, p. 425-442.

SORTINO, F. \& VAN DER MEER, R. (1991). Downside risk. The journal of Portfolio Management, p. 27-31.

TOBIN, J. (1958). "Liquidity Preference as Behavior towards Risk". Review of Economic Studies, n. 25, p. 65-86.

TREYNOR, J. (1965). How to Rate Management of Investment Funds. Harvard Business Review, n. 43, p. 63-75.

TREYNOR, J. L. (1965). Toward a Theory of Market Value of Risk Assets.

(unpublished manuscript, undated). 